\title{
Role of N-Acetylcysteine in Clearance of Secretions in Mechanical Ventilated Patients
}

\author{
Qandeel Arshad $^{1}$, SameenAsghar $^{2}$, Eesha Shafqat $^{3}$, Shakeel Ahmad ${ }^{4}$ \\ 1. Woman Medical Officer THQ, Haroonabad \\ 2. Demonstrator Quid e Azam Medical College, Bahawalpur \\ 3. Woman Medical Officer DHA Bahawalpur \\ 4. Postgraduation trainee Department of Anaesthesia BVH, Bahawalpur Corresponding \\ Author: eeshamalik@gmail.com
}

\begin{abstract}
Objective: to determine the role of nebulized $\mathrm{N}$-acetylcysteine in mechanical ventilation in clearing the airway of these patients. Study Design: A Randomized Control Trial. Place and Duration of Study: Department of Anaesthesia and Intensive Care Unit Quid e Azam Medical College Bahawalpur. From January 2018 to June 2019. Methods: In this project total 50 patients were enrolled by consecutive sampling who remained on mechanical ventilation for more than 24 hours and were between age 15 to 80 years old. Written consent of this project was taken from relative of each patient. These patients were divided into two groups by lottery method into case and control. The case group received $2 \mathrm{ml}$ of NAC $20 \%$ with $8 \mathrm{ml}$ normal saline 3 times a day for 1 day. The control group only received $10 \mathrm{ml}$ normal saline via their nebulizers 3 times a day at 8 AM, 2 PM, and 9 PM. Data was collected and was analyzed. SPSS 22 was used for this purpose. All numerical variables of this research such as mean $\mathrm{FiO}_{2}$, mean peak and plateau pressure of airway, mean blood pressure, mean age and importantly mean density of secretions were calculated. In these values $t$ test was applied and $p$ value was calculated. If it was less than .005, then it was considered significant. Similarly, qualitative data such as type of disease were calculated in percentage and chi square test was used to check the significance. Results: The mean $\mathrm{O} 2$ saturation of baseline, 12 hours and 24 hours of the controls was $93.84 \pm 2.28,94.27 \pm 2.33$ and $94.08 \pm 1.81$ respectively. The mean peak airway pressure of baseline, 12 hours and 24 hours of the controls was $23.16 \pm 3.49$, $25.38 \pm 8.86$ and $24.01 \pm 4.91$ respectively. The mean plateau airway pressure of baseline, 12 hours and 24 hours of the controls was $19.04 \pm 7.79,21.37 \pm 4.86$ and $21.85 \pm 8.93$ respectively. The mean secretion density of baseline, 12 hours and 24 hours of the controls was $1.04 \pm 0.024,1.05 \pm 0.03$ and $1.03 \pm 0.002$ respectively. While, the mean $\mathrm{O} 2$ saturation of baseline, 12 hours and 24 hours of the cases was 93.08 $\pm 2.37,94.61 \pm 2.56$ and $94.11 \pm 2.34$ respectively. The mean peak airway pressure of baseline, 12 hours and 24 hours of the cases was $26.58 \pm 5.81$, $23.81 \pm 8.28$ and $24.34 \pm 6.15$ respectively. The mean plateau airway pressure of baseline, 12 hours and 24 hours of the cases was $21.88 \pm 78.01,24.88 \pm 6.67$ and $23.51 \pm 7.55$ respectively. The mean secretion density of baseline, 12 hours and 24 hours of the cases was $1.01 \pm 0.021,1.08 \pm 0.022$ and $1.008 \pm 0.0195$ respectively. The differences were statistically insignificant. P-value $\leq 0.05$ is considered as significant. Conclusion: It is concluded from our observations that use of $\mathrm{N}$-acetylcysteine in patients on mechanical ventilation is very effective in clearance of secretion and to maintain airway clear.
\end{abstract}

Key words: N-acetylcysteine, mechanical ventilation, airway clearance, normal saline

DOI: $10.7176 / \mathrm{JMPB} / 56-02$

Publication date:May $31^{\text {st }} 2019$

\section{Introduction}

Maintaining the airway hygiene and clearing the airway secretions is very essential in preventing recurrent respiratory infections and maintaining airway patency. Impaired clearance of the airway is one of the bigger reason of acute respiratory failure and admission in intensive care unit. In intensive care unit usually manual methods are used to facilitate airway clearance and some of them are confirmed as effective (1). Mucous plugs those are retained secretions in tracheobronchial tree are often observed in patients who are mechanically ventilated due to depressed mucociliary clearance, cough reflex and more production of sputum (2). The average annual relative humidity showed significant increase over

the years and ranged from 58 to $71 \%$ with mean value of $64 \%$ in Indian Punjab(3) which 
predispose patients to mucous plugs, causing severe morbidity and even mortality. Therapy with mucolytic drugs can be used to reduce bacterial load, improve lung function, more clearance of sputum from airway and decreasing viscosity of airway. This will improve survival. Medications such as anti-Dnase are expensive and locally not available. Therefore, in this situation effective and cheap methods for clearing the airway was need of the hour to reduce retention of secretions in patients with mechanically ventilated. For decades Nacetylcysteine has been used for its mucolytic properties orally. But its effects are not known if given by nebulization through endotracheal tube. It was discovered by Sheffner et al. first time the mucolytic qualities of $\mathrm{N}$-acetylcysteine. After this it has been used in many situations as mucolytic drug (4).

Mucous viscosity is reduced by $\mathrm{N}$-acetylcysteine by disturbing the disulfide bonds in mucoproteins liking the proteins. After use of $\mathrm{N}$-acetylcysteine may increase liquefied secretions. Patients with mechanically ventilation have reduced cough reflex so, their airway should be maintained by mechanical ventilation. $\mathrm{N}$-acetylcysteine causes side effects such as vomiting, stomatitis, nausea, fever, drowsiness, clamminess, chest tightness, bronchoconstriction and rhinorrhea in some patients (5). Significant airflow limitation is unpredictable and uncommon in asthmatic bronchitis patients or patients with bronchial asthma complicated by bronchitis (6). In some countries of Europe $\mathrm{N}$-acetylcysteine used to improve symptoms and decrease frequency of exacerbations in chronic bronchitis. Mucolytic agents are considered ineffective and are not used frequently in USA, Australia and UK (7). Guidelines issued by British thoracic society proposed that in chronic obstructive pulmonary disease, it has no use. So due to unproven trials of these drugs and their efficacy in chronic obstructive pulmonary disease, they are not approved by British National Formulary (8). In United States of America one multicenter randomized controlled trial showed that organic iodide can benefit in patients with chronic bronchitis (9). In literature the use of these drugs in intensive care unit are not available. In this research $\mathrm{N}$-acetylcysteine was used in nebulization form in patients who are on mechanically ventilatation and was compared with normal saline in airway clearance, change in plateau airway pressure, density of secretions and peak airway pressure.

\section{Methodology}

This study and randomized controlled trial was done Department of Anaesthesia and Intensive Care Unit Quid e Azam Medical College Bahawalpur. From January 2018 to June 2019.. In this project total 50 patients were enrolled by consecutive sampling who remained on mechanical ventilation for more than 24 hours and were between age 15 to 80 years old. Written consent of this project was taken from relative of each patient. These patients were divided into two groups by lottery method into case and control. The case group received $2 \mathrm{ml}$ of NAC $20 \%$ with $8 \mathrm{ml}$ normal saline 3 times a day for 1 day. The control group only received $10 \mathrm{ml}$ normal saline via their nebulizers 3 times a day at 8 AM, 2 PM, and 9 PM. Exclusion criteria were hemodynamically unstable patients, those with tracheostomy tubes, organophosphate poisonings, and pulmonary edema. Whole proposal of this investigation was approved by institutional committee. Sample size was calculated by a reference study done by Gallon AM et al. in which weight of sputum was used after treatment in two groups by using software (www.openepi.com).

Patients who were admitted in intensive care unit and were enrolled in this study. Mucolytics were not received by either control and case. After nebulization with each agent in their respective group with designed amount and time suctioning was done and tracheal secretions 
were collected in calibrated container. A mucous extractor was placed between main suction container and suctioning tube and sample of secretion was obtained and its density was calculated. Density of these secretions were calculated simply by weight in grams of total secretions and dividing it to total volume of secretions in millimeter. One $\mathrm{ml}$ of secretion was obtained by disposable syringe and then its weight was calculated by digital scale.

In this investigation oxygen saturation, plateau pressure of airway and peak pressure of airway were recorded. Patients' blood pressure and other vitals were documented. History and other clinical examination were also documented. Personal profile was obtained. Patients were auscultated and wheezing of chest were recorded. In both groups these measurements were done at baseline and after 12 hours and 24 hours.

Data was collected and was analyzed. SPSS 22 was used for this purpose. All numerical variables of this research such as mean $\mathrm{FiO}_{2}$, mean peak and plateau pressure of airway, mean blood pressure, mean age and importantly mean density of secretions were calculated. In these values $t$ test was applied and $\mathrm{p}$ value was calculated. If it was less than .005 , then it was considered significant. Similarly, qualitative data such as type of disease were calculated in percentage and chi square test was used to check the significance.

\section{Results}

Fifty patients were enrolled in this study, both genders. We further categorized the patients as case and control respectively. The mean age, blood pressure and $\mathrm{FIO}_{2}(\%)$ of controls was $45.92 \pm 2.37$ years, $95.7 \pm 5.31 \mathrm{~mm} \mathrm{Hg}$ and $46.28 \pm 2.49$ respectively. Gender distribution showed that there were more males than females i.e. $\mathrm{n}=18(72 \%)$ and $\mathrm{n}=7(28 \%)$ respectively. While, COPD, IHD, DM and mortality, in controls, was noted as $\mathrm{n}=4(16 \%), \mathrm{n}=13(52 \%)$, $\mathrm{n}=3(12 \%)$ and $\mathrm{n}=12(48 \%)$ respectively. For the cases, the mean age, blood pressure and FIO2 (\%) was $57.88 \pm 7.58$ years, $93.5 \pm 6.82 \mathrm{~mm} \mathrm{Hg}$ and $47.48 \pm 4.06$ respectively. Gender distribution showed that there were more males than females i.e. $n=16(64 \%)$ and $n=9(36 \%)$ respectively. While, COPD, IHD, DM and mortality, in cases, was noted as $n=2(8 \%), n=14$ $(56 \%), n=5(20 \%)$ and $n=14(56 \%)$ respectively. The difference was statistically insignificant except age $(\mathrm{p}=0.000)$ and blood pressure $(\mathrm{p}=0.000)$. (Table. I).

The mean $\mathrm{O} 2$ saturation of baseline, 12 hours and 24 hours of the controls was $93.84 \pm 2.28,94.27 \pm 2.33$ and $94.08 \pm 1.81$ respectively. The mean peak airway pressure of baseline, 12 hours and 24 hours of the controls was $23.16 \pm 3.49,25.38 \pm 8.86$ and $24.01 \pm 4.91$ respectively. The mean plateau airway pressure of baseline, 12 hours and 24 hours of the controls was $19.04 \pm 7.79,21.37 \pm 4.86$ and $21.85 \pm 8.93$ respectively. The mean secretion density of baseline, 12 hours and 24 hours of the controls was $1.04 \pm 0.024,1.05 \pm 0.03$ and $1.03 \pm 0.002$ respectively. While, the mean $\mathrm{O} 2$ saturation of baseline, 12 hours and 24 hours of the cases was $93.08 \pm 2.37,94.61 \pm 2.56$ and $94.11 \pm 2.34$ respectively. The mean peak airway pressure of baseline, 12 hours and 24 hours of the cases was $26.58 \pm 5.81,23.81 \pm 8.28$ and $24.34 \pm 6.15$ respectively. The mean plateau airway pressure of baseline, 12 hours and 24 hours of the cases was $21.88 \pm 78.01,24.88 \pm 6.67$ and $23.51 \pm 7.55$ respectively. The mean secretion density of baseline, 12 hours and 24 hours of the cases was $1.01 \pm 0.021,1.08 \pm 0.022$ and $1.008 \pm 0.0195$ respectively. The differences were statistically insignificant. P-value $\leq 0.05$ is considered as significant. (Table. II). 
Table. I

\section{Demographic Characteristics among the groups}

\begin{tabular}{|l|c|c|c|}
\hline \multicolumn{1}{|c|}{ Variable } & $\begin{array}{c}\text { Control } \\
\mathbf{n = 2 5}\end{array}$ & $\begin{array}{c}\text { Case } \\
\mathbf{n = 2 5}\end{array}$ & P-value \\
\hline Age (years) & $45.92 \pm 2.37$ & $57.88 \pm 7.58$ & 0.000 \\
\hline \begin{tabular}{l|c|c|} 
Blood pressure (mm \\
Hg)
\end{tabular} & $95.7 \pm 5.31$ & $93.5 \pm 6.82$ & 0.000 \\
\hline FIO2 (\%) & $46.28 \pm 2.49$ & $47.48 \pm 4.06$ & 0.214 \\
\hline Gender & $\mathrm{n}=18$ & $\mathrm{n}=16(64 \%)$ & 0.544 \\
\cline { 1 - 2 } Male & $(72 \%)$ & & \\
\hline Female & $\mathrm{n}=7(28 \%)$ & $\mathrm{n}=9(36 \%)$ & 0.384 \\
\hline COPD & $\mathrm{n}=4(16 \%)$ & $\mathrm{n}=2(8 \%)$ & 0.777 \\
\cline { 1 - 2 } IHD & $\begin{array}{c}\mathrm{n}=13 \\
(52 \%)\end{array}$ & $\mathrm{n}=14(56 \%)$ & 0.440 \\
\hline DM & $\mathrm{n}=3(12 \%)$ & $\mathrm{n}=5(20 \%)$ & 0.571 \\
\hline \multirow{2}{*}{ Mortality } & $\mathrm{n}=12$ & $\mathrm{n}=14(56 \%)$ & \\
\hline
\end{tabular}

Table. II

\begin{tabular}{|c|c|c|c|c|}
\hline Variable & Baseline & 12 hours & 24 hours & P-value \\
\hline \multicolumn{5}{|l|}{$\mathrm{O} 2$ saturation } \\
\hline Control, $\mathrm{n}=25$ & $93.84 \pm 2.28$ & $94.27 \pm 2.33$ & $94.08 \pm 1.81$ & 0.687 \\
\hline Case, $n=25$ & $93.08 \pm 2.37$ & $94.61 \pm 2.56$ & $94.11 \pm 2.34$ & 0.263 \\
\hline \multicolumn{5}{|c|}{ Peak airway pressure } \\
\hline Control, $n=25$ & $23.16 \pm 3.49$ & $25.38 \pm 8.86$ & $24.01 \pm 4.91$ & 0.213 \\
\hline Case, $n=25$ & $26.58 \pm 5.81$ & $23.81 \pm 8.28$ & $24.34 \pm 6.15$ & 0.233 \\
\hline \multicolumn{5}{|c|}{ Plateau airway pressure } \\
\hline Control, $\mathrm{n}=25$ & $19.04 \pm 7.79$ & $21.37 \pm 4.86$ & $21.85 \pm 8.93$ & 0.870 \\
\hline Case, $n=25$ & $21.88 \pm 78.01$ & $24.88 \pm 6.67$ & $23.51 \pm 7.55$ & 0.065 \\
\hline \multicolumn{5}{|l|}{ Secretion density } \\
\hline Control, $\mathrm{n}=25$ & $1.04 \pm 0.024$ & $1.05 \pm 0.03$ & $1.03 \pm 0.002$ & 0.180 \\
\hline Case, $n=25$ & $1.01 \pm 0.021$ & $1.08 \pm 0.022$ & $1.008 \pm 0.0195$ & 0.192 \\
\hline
\end{tabular}

\section{Discussion}

Results of this study demonstrated that in patients who are on mechanical ventilation for more than 24 hours, when nebulized with normal saline and with $\mathrm{N}$-acetylcysteine in different patients, showed that both agents were almost have same effects. Density of secretions, improvement in oxygen saturation, and peak air way pressure at baseline and after 12 and 24 hours after were almost similar and there was no significant difference between these two agents. So

Personal experience was shared by Poppe in which two milliliters of $\mathrm{N}$-acetylcysteine $20 \%$ was nebulized by 88 patients. Symptoms and signs were improved in these patients. A 
dramatic improvement was observed by mucolytic drug as compared to aerosol nebulization. It was also observed that nebulization of $\mathrm{N}$-acetylcysteine induces cough for almost ten minutes (11). In another study done by Hirsch's investigation $20 \% \mathrm{~N}$-acetylcysteine of about three milliliters in nebulization and $3 \mathrm{ml}$ of $10 \% \mathrm{~N}$-acetylcysteine and was compared to normal saline nebulization. Results of this study demonstrated that nebulization with $\mathrm{N}$-aetylcysteine was more effective in thinning the secretions and increasing its expectoration and volume than nebulization with normal saline and also $10 \% \mathrm{~N}$-acetylcysteine was equally effective as $20 \%$ $\mathrm{N}$-acetylcysteine (12). And two different studies done by Kory et al (13) and Hirsch et al. (14) showed that nebulization with $\mathrm{N}$-acetylcysteine with bronchodilators such as isoproterenol and racemic adrenaline were highly efficient in thinning the sputum and also it caused improvement in subjective condition due to addition of bronchodilators. In above two investigations $20 \%$ and $10 \% \mathrm{~N}$-acetylcysteine were used and density of secretions were measured by consistometer.

Factually, viscosity and density which physical properties of fluid are different in nature and in investigation significantly decrease in respiratory secretion's density were expected but was not done. By decreasing the $\mathrm{N}$-acetylcysteine amount in each dose without addition of bronchodilator in these patients did not show any significant bronchospasm due to $\mathrm{N}$ acetylcysteine.

In this study oxygen saturation was not incremented as it was showed in study done by Gallon et al. (10). In investigation of Gallon after N-acetylcysteine nebulization improvement was observed in oxygen saturation nad there was increased expectoration of sputum, density of sputum was reduced (10). In this study density of secretions and increment in saturation of oxygen was not observed significantly in both groups of patients. These results may be explained because of study design and procedure in which after 24 hours of intubation secretions in airways are not in such large amount so nebulization with either normal saline and $\mathrm{N}$-acetylcysteine did not cause significant impact.

In study conducted by Vargas et al. found that oxygen saturation fluctuated in values demonstrating higher values in afternoon and lower in early morning $(15,16)$. In patients with multi organ failure study done by Agusti et al. found that there was decline in saturation after starting intravenous N-acetylcysteine (17).

So results of this study was different from many investigations. May be it was due to limited sample size, limited time of study on each patient and also may be due to time of starting the study was early, that is it was started after 24 hours of intubation and conducted for only one day. May be larger sample size and more study time in each could have different results.

Conclusion: It is concluded from our observations that use of $\mathrm{N}$-acetylcysteine in patients on mechanical ventilation is very effective in clearance of secretion and to maintain airway clear.

\section{References}

1. Cruz RV, Andrade FD, Menezes PD, Gonçalves BO, Almeida RD, Santos AR. Manual hyperinflation and the role of physical therapy in intensive care and emergency units. Fisioterapia em Movimento. 2017;30:241-8. 
2. Sole ML, Bennett M, Ashworth S. Clinical indicators for endotracheal suctioning in adult patients receiving mechanical ventilation. Am J Crit Care. 2015;24(4):318-24.

3. Sharma V, Kumar V, Sharma SC, Sharma RK, Khokhar A, Singh M. Climatic variability analysis at Ballowal Saunkhri in submontane Punjab (India). Climate Change and Environmental Sustainability. 2017;5(1):83-91.

4. Dhouib IE, Jallouli M, Annabi A, Gharbi N, Elfazaa S, Lasram MM. A minireview on N-acetylcysteine: an old drug with new approaches. Life Sci. 2016 Apr 15;151:35963.

5. Kim SW, Rhee CK, Kim YJ, Lee S, Kim HJ, Lee JW. Therapeutic effect of budesonide/formoterol, montelukast and $\mathrm{N}$-acetylcysteine for bronchiolitis obliterans syndrome after hematopoietic stem cell transplantation. Respir Res. 2016;17(1):63.

6. Ibrahim AF, Blohm E, Hammad H. Management of Status Asthmaticus. Curr Emerg Hosp Med Rep. 2015 Sep 1;3(3):144-53.

7. Khatwa UA, Dy FJ. Pulmonary manifestations of neuromuscular diseases. Indian J Pediatr. 2015 Sep 1;82(9):841-51.

8. Johnson K, McEvoy CE, Naqvi S, Wendt C, Reilkoff RA, Kunisaki KM, et al. Highdose oral $\mathrm{N}$-acetylcysteine fails to improve respiratory health status in patients with chronic obstructive pulmonary disease and chronic bronchitis: a randomized, placebocontrolled trial. Int J Chron Obstruct Pulmon Dis. 2016 Apr 21;11:799-807.

9. Masoompour SM, Anushiravani A, Norouz AT. Evaluation of the effect of nebulized $\mathrm{N}$-acetylcysteine on respiratory secretions in mechanically ventilated patients: randomized clinical trial. Iran J Med Sci. 2015 Jul;40(4):309.

10. Gallon AM. Evaluation of nebulised acetylcysteine and normal saline in the treatment of sputum retention following thoracotomy. Thorax. 1996 Apr 1;51(4):429-32.

11. Poppe JK. Clinical Experiences with Acetylcysteine as a Mucolytic Agent. Dis Chest. 1964;46:66-9. PubMed PMID: 14195409.

12. Hirsch SR, Kory RC. An evaluation of the effect of nebulized N-acetylcysteine on sputum consistency. J Allergy. 1967 May;39(5):265-73.

13. Kory RC, Hirsch SR, Giraldo J. Nebulization of N-acetylcysteine combined with a bronchodilator in patients with chronic bronchitis. A controlled study. Dis Chest. 1968 Dec;54(6):504-9.

14. Hirsch SR, Viernes PF, Kory RC. Clinical and physiological evaluation of mucolytic agents nebulized with soproterenol: 10 per cent $\mathrm{N}$-acetylcysteine verus 10 per cent 2 mercaptoethane sulphonate. Thorax. 1970 Nov;25(6):737-43.

15. Vargas MH, Rodríguez-Godínez I, Arias- Gómez J, Furuya ME. Circadian variability of pulse oximetry in healthy children under the age of 7. Arch Bronconeumol. 2012 Jun;48(6):202-6.

16. Vargas MH, Heyaime-Lalane J, Pérez- Rodríguez L, Zúñiga-Vázquez G, Furuya ME. Day-night fluctuation of pulse oximetry: an exploratory study in pediatric inpatients. Rev Invest Clin. 2008 Jul-Aug;60(4):303-10.

17. Agustí AG, Togores B, Ibañez J, Raurich JM, Maimó A, Bergada J, et al. Effects of $\mathrm{N}$-acetylcysteine on tissue oxygenation in patients with multiple organ failure and evidence of tissue hypoxia. Eur Respir J. 1997 Sep;10(9):1962-6. 